\title{
Silver/silver chloride electrodes for measurement of potential difference in human bronchi
}

Isabelle Fajac, Jacques Lacronique, Alain Lockhart, Josette Dall'Ava-Santucci, Daniel J Dusser

\begin{abstract}
Background-An easy and reliable method to measure potential difference (PD) in the lower airways would be of interest in the field of cystic fibrosis. We have developed silver/silver chloride (Ag/ AgCl) electrodes to measure PD in the lower airways.

Methods-To validate this technique the nasal PD measured with Ag/AgCl electrodes and with conventional perfused electrodes was compared in 16 patients. The range of $\mathrm{PD}$ measured with $\mathrm{Ag} / \mathrm{AgCl}$ electrodes in the lower airways during fibreoptic bronchoscopy was determined in 14 adult patients and in nine the reproducibility of this technique was examined.
\end{abstract}

Results-Nasal PD values measured with Ag/AgCl and perfused electrodes were highly correlated $(r=0.985, \mathrm{p}<0.0001)$ and the limits of agreement (mean $\pm 2 S D$ of the difference) between the two methods were $-1.91 \mathrm{mV}$ and $1.53 \mathrm{mV}$. In the lower airways a progressive and slight decrease in PD values with decreasing airway diameter was observed in most patients. The mean (2SD) of the differences between the two tracheal measurements was 0.21 (1.73) $\mathrm{mV}$.

Conclusions-The use of Ag/AgCl electrodes gives a reliable and reproducible measurement of PD in the lower airways in humans.

(Thorax 1998;53:879-881)

Department of
Respiratory Physiology

I Fajac

A Lockhart

J Dall'Ava-Santucci

Department of Respiratory Medicine $\mathrm{J}$ Lacronique

D J Dusser

Cochin Hospital, René Descartes University, Paris, France

Address for correspondence: Dr I Fajac, Laboratoire de Physiologie Respiratoire,

UFR Cochin Port-Royal,

24 rue du Faubourg

Saint-Jacques, 75014 Paris,

France.

Received 25 November 1997

Returned to authors

5 March 1998

Revised version received

3 April 1998

Accepted for publication

19 May 1998 measure PD easily in the lower airways, few studies published a decade ago have attempted to measure PD in the bronchi. ${ }^{4-6}$ In these studies PD was recorded during fibreoptic bronchoscopy with the same type of Ringer's perfused electrodes as are used in the nose. With these electrodes we have attempted to measure transepithelial PD in the lower airways of eight subjects during fibreoptic bronchoscopy. However, in this preliminary study we found it difficult to obtain stable and reproduc- ible PD values in the lower airways, mostly because of air bubbles that formed at the tip of the very thin electrode and because of an early flooding of the airway lumen by the perfused fluid. In the present study we have therefore prepared silver/silver chloride $(\mathrm{Ag} / \mathrm{AgCl})$ nonpolarisable electrodes to measure more easily transepithelial PD in the lower airways.

\section{Methods}

EXPERIMENTAL DESIGN AND SUBJECTS

The agreement between $\mathrm{Ag} / \mathrm{AgCl}$ electrodes and perfused electrodes was determined by measurement of nasal PD with both methods in 16 adult patients (six men) of mean (SD) age 51 (19) years. The range of PD in the lower airways was determined with $\mathrm{Ag} / \mathrm{AgCl}$ electrodes in 14 adult patients (six men) of mean (SD) age 60 (19) years during fibreoptic bronchoscopy required because of lung cancer $(n=8)$ or interstitial lung disease $(n=6)$. In nine of these 14 patients the reproducibility of PD measurements with $\mathrm{Ag} / \mathrm{AgCl}$ electrodes was determined by two measurements at five minute intervals at the same location of the distal trachea.

The investigation conformed to the regulations of the Institutional Ethics Committee.

PREPARATION OF AG/AGCL WIRE ELECTRODES Silver wires were used to prepare the $\mathrm{Ag} / \mathrm{AgCl}$ electrodes (World Precision Instruments, Hertfordshire, UK). The silver wire was inserted into a Teflon catheter (Bioblock Scientific, Illkirch, France; fig 1). The end of the silver wire was heated to form a small atraumatic bead which was covered by a layer of silver chloride by anodising in $\mathrm{HCl}$ solution using a potentiostat/galvanostat. Two new $\mathrm{Ag} / \mathrm{AgCl}$ electrodes were prepared for each patient and sterilised by autoclaving. One served as a reference bridge and the silver bead was taped on to a scarification on the skin at the anterior face of the forearm. The other electrode served as the exploring bridge and the silver bead allowed the contact with the airway wall. Both branches of the bridge were connected to a high impedance millivoltmeter. especially in gene therapy studies to be able to
MEASUREMENT OF TRANSEPITHELIAL PD IN THE NOSE AND THE LOWER AIRWAYS

Before each measurement bridge conductivity was verified. For measurement of nasal PD each patient underwent two measurements in random order, one with $\mathrm{Ag} / \mathrm{AgCl}$ electrodes and the other with conventional electrodes perfused with Ringer's lactate and prepared as previously described. ${ }^{7}$ The exploring electrode was positioned $3-4 \mathrm{~cm}$ from the anterior tip of 
Figure 1 Scheme of the $\mathrm{Ag} / \mathrm{AgCl}$ electrode that was devised for the present study. Outside diameter $1.93 \mathrm{~mm}$.
Figure 2 Agreement between $\mathrm{Ag} / \mathrm{AgCl}$ electrodes and conventional perfused electrodes for nasal potential difference (PD)

measurement in 16 subjects. (A) Correlation between nasal PD measured with $\mathrm{Ag} / \mathrm{AgCl}$ electrodes and with perfused electrodes ( - = regression line, --- = line of identity). (B) Difference between nasal PDs measured with perfused electrodes and with $\mathrm{Ag} / \mathrm{AgCl}$ electrodes (4 nasal PD) plotted against mean of nasal PDs measured with both methods. $\bullet=$ patients with cystic fibrosis, $\mathrm{O}=$ patients with bronchiectasis, and - healthy subjects.

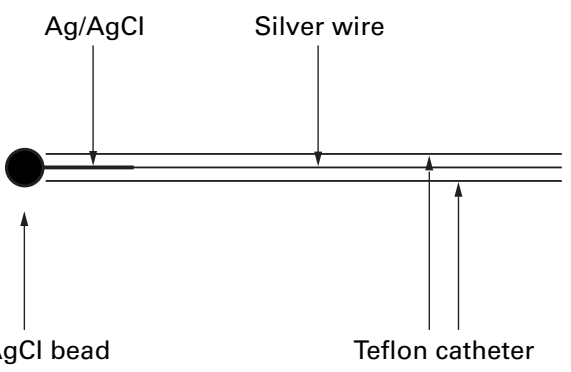

the turbinate until a maximal and stable PD for over $10 \mathrm{~s}$ was obtained. Measurements of PD in the lower airways were made with $\mathrm{Ag} / \mathrm{AgCl}$ electrodes under general anaesthesia (propofol and lidocaïne $2 \%$ ). No local anesthesia was used. PDs were measured with the exploring electrode inserted through the suction channel of the fibreoptic bronchoscope and positioned on the airway surface of the different bronchi.

STATISTICAL ANALYSIS

PDs were negative and were expressed as absolute values. Nasal PD was expressed as the arithmetic mean of the values of the two nostrils. Statistical analysis was performed according to Bland and Altman. ${ }^{8}$

\section{Results}

Measurement of PDs with $\mathrm{Ag} / \mathrm{AgCl}$ electrodes in the nose and the lower airways proved to be safe, easy, and gave stable values.

AGREEMENT BETWEEN AG/AGCL ELECTRODES AND PERFUSED ELECTRODES FOR NASAL PD

MEASUREMENTS

The range of nasal PDs was 10.4-33.1 mV (median 14.0) with perfused electrodes and 9.6-32.4 mV (median 13.4) with $\mathrm{Ag} / \mathrm{AgCl}$ electrodes. Nasal PDs measured with $\mathrm{Ag} / \mathrm{AgCl}$ and perfused electrodes were highly correlated $(r=$ $0.985, \mathrm{p}<0.0001$ ) (fig $2 \mathrm{~A}$ ). The mean (SD) bias

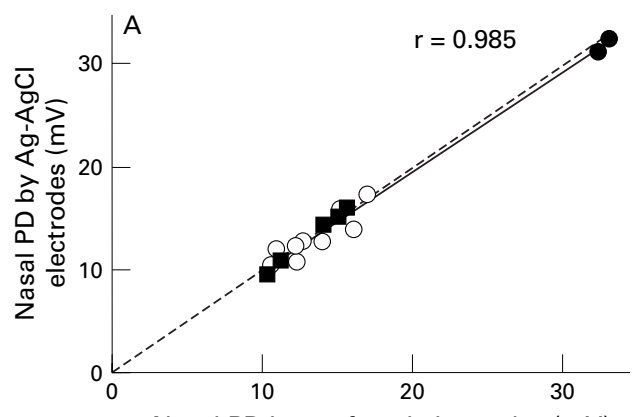

Nasal PD by perfused electrodes $(\mathrm{mV})$

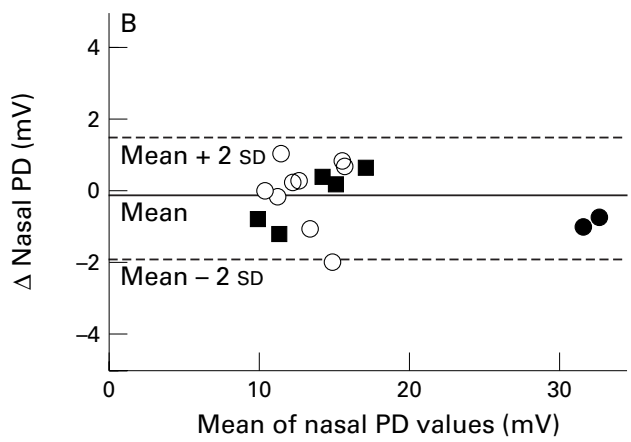

of the differences was $-0.19(0.86) \mathrm{mV}$ and the limits of agreement (mean $\pm 2 \mathrm{SD}$ of the difference) between the two methods were $-1.91 \mathrm{mV}$ and $1.53 \mathrm{mV}$. The range of the differences was -2 to $1 \mathrm{mV}$ (fig $2 \mathrm{~B}$ ). The $95 \%$ confidence interval for the lower limits of agreement was -2.70 to $-1.12 \mathrm{mV}$ and for the upper limits was 0.74 to $2.32 \mathrm{mV}$. Thus, the mean difference between the two methods was close to zero and the limits of agreement were small enough to demonstrate the validity of $\mathrm{Ag} / \mathrm{AgCl}$ electrodes for measurement of the transepithelial PD in the airways.

DETERMINATION OF THE NORMAL RANGE OF TRANSEPITHELIAL PD IN THE LOWER AIRWAYS WITH AG/AGCL ELECTRODES

A precise location of the bead was easily secured. A progressive but slight decrease in PDs with decreasing airway diameter was observed in most patients and for the group as a whole: mean (SE) in distal trachea, $13.4(1.7) \mathrm{mV}$; in main stem bronchi, $12.3(1.8) \mathrm{mV}$; in lobar bronchi, 12.5 (5.2) $\mathrm{mV}$; in segmental and subsegmental bronchi, 10.6 (3.1) $\mathrm{mV}$.

REPRODUCIBILITY OF PD MEASUREMENTS IN THE DISTAL TRACHEA USING AG/AGCL ELECTRODES The mean (SD) difference was $0.21(0.86) \mathrm{mV}$ and the coefficient of reproducibility ${ }^{9}$ was $1.73 \mathrm{mV}$. These results demonstrate a good reproducibility of the method using $\mathrm{Ag} / \mathrm{AgCl}$ electrodes for transepithelial PD measurements in the trachea.

\section{Discussion}

Commercially available $\mathrm{Ag} / \mathrm{AgCl}$ electrodes are currently used in cardiography to measure monophasic action potentials. Their low polarisation properties ensure reliable potential measurements and they have already been used for measurements of nasal PD. ${ }^{10}$ As our $\mathrm{Ag} / \mathrm{AgCl}$ electrodes were devised to measure PDs in the lower airways, we did not find any advantage over the perfusion technique of these electrodes in the nose. However, in the lower airways the $\mathrm{Ag} / \mathrm{AgCl}$ electrodes allowed reliable and reproducible PD measurements. It is noteworthy that the reproducibility we have observed in the lower airways with $\mathrm{Ag} / \mathrm{AgCl}$ electrodes was similar to the one described with the usual perfusion technique in the nose. ${ }^{2}{ }^{10}$

One drawback of $\mathrm{Ag} / \mathrm{AgCl}$ electrodes is that the silver chloride layer which gives the electrode its distinctive black coloration and its low polarisation properties disappears with rubbing. This is why new electrodes had to be used for each patient and they could not be just washed and sterilised after each use. This drawback was offset by their non-perfused property, their easy use in the lower airways, and the stable and reproducible PD measurements they allowed. The silver bead was easily seen and placed precisely against the airway wall.

Although our study was performed on a small number of subjects, the use of $\mathrm{Ag} / \mathrm{AgCl}$ electrodes appear to provide a reliable, reproducible and easy method for measurement of transepithelial PD in the lower airways. As this method will be applied almost uniquely in 
cystic fibrosis, it needs to be validated in patients with cystic fibrosis and should be adapted to measure PDs during pharmacodynamic tests. However, it may prove a useful technique for the study of ion transport mechanisms in the lower airways and for the assessment of the functional efficacy of in vivo gene transfer in cystic fibrosis.

We are grateful to Dr E Coraboeuf for helpful technical discussion and advice, D Pelé (Atelier Biomédical, Cochin Hospital) and S Remeur for technical assistance. The study was supported by the Association Française de Lutte contre la Mucoviscidose (AFLM).

1 Boucher RC. Human airway ion transport, part I. $A m \mathcal{F}$ Respir Crit Care Med 1994;150:271-81.

2 Knowles MR, Carlson JL, Collier AM, et al. Measurements of nasal transepithelial electric potential differences in normal human subjects in vivo. Am Rev Respir Dis 1981;124: 484-90.
3 Knowles M, Gatzy J, Boucher R. Increased bioelectric potential difference across respiratory epithelia in cystic potential difference across respiratory ep
fibrosis. N Engl f Med 1981;305:1489-95.

4 Knowles MR, Buntin WH, Bromberg PA, et al. Measurements of transepithelial electric potential differences in the trachea and bronchi of human subjects in vivo. Am Rev Respir Dis 1982;126:108-12.

5 Alton EWFW, Batten J, Hodson M, et al. Absence of electrochemical defect of cystic fibrosis in transplanted lung (letter). Lancet 1987;i:1026.

6 Wood A, Higenbottam T, Jackson M, et al. Airway mucosal bioelectric potential difference in cystic fibrosis after lung transplantation. Am Rev Respir Dis 1989;140:1645-9.

7 Mialon P, Charfi R, Regnard J, et al. Locally deposited but not inhaled frusemide reduces nasal potential difference in healthy subjects. Eur f Clin Pharmacol 1993;45:347-51.

8 Bland JM, Altman DG. Statistical methods for assessing agreement between two methods of clinical measurement. Lancet 1986;i:307-10.

9 British Standards Institution. Precision of test methods. I: Guide for the determination and reproducibility for a standard test method (BS 5497, part I). London: BSI, 1979.

10 Hofmann T, Böhmer O, Hüls G, et al. Conventional and modified nasal potential-difference measurement in cystic fibrosis. Am 7 Respir Crit Care Med 1997;155:1908-13.42-8.

Thorax 1998;53:881-883

\title{
Endogenous nitric oxide in patients with stable COPD: correlates with severity of disease
}

\author{
Enrico Clini, Luca Bianchi, Marco Pagani, Nicolino Ambrosino
}

Fondazione Salvatore Maugeri IRCCS,

Servizio di

Fisiopatologia

Respiratoria, Divisione

di Pneumologia,

Centro Medico di

Gussago (BS), Italy

E Clini

L Bianchi

M Pagani

N Ambrosino

Correspondence to: Dr E Clini, Fondazione S. Maugeri IRCCS,

Fisiopatologia e Fisioterapia Respiratoria, Day Hospital

Pneumologico, Divisione di

Pneumologia, Centro

Medico,Via Pinidolo 23,

25064 Gussago (BS), Italy.

Received 18 November 1997 Returned to authors 10 March 1998 Revised version received 18 May 1998 Accepted for publication 20 May 1998

\begin{abstract}
Background-Increased levels of exhaled nitric oxide (eNO) have been reported in asthmatic subjects but little information is available on eNO in patients with advanced chronic obstructive pulmonary disease (COPD). A study was undertaken to evaluate the levels of eNO in patients with stable COPD of different degrees of severity.

Methods-Peak and plateau values of eNO (PNO and PLNO, respectively) were evaluated in 53 patients with COPD and analysed according to the level of forced expiratory volume in one second $\left(F_{E V}\right)$ and the presence of cor pulmonale (CP) (group 1, $\mathrm{FEV}_{1}<35 \%$ predicted with $\mathrm{CP}$, $\mathbf{n}$ $=15 ;$ group $2, \mathrm{FEV}_{1}<35 \%$ predicted without $\mathrm{CP}, \mathbf{n}=15$; group $3, \mathrm{FEV}_{1}>35 \%$ predicted, $n=23$ ). Seventeen normal subjects served as controls.

Results-All the patients with COPD had reduced levels of PLNO compared with the controls (mean (SD) 6.3 (3.0) and 9.4 (2.8) ppb, respectively). In groups 1 and 2 PLNO levels were significantly lower than in subjects in group 3 (5.5 (2.9), 5.7 (3.5), and 7.1 (2.7) ppb, respectively; $\mathbf{p}<0.01$ ANOVA). In all subjects \% predicted $F_{1}$ correlated slightly with PLNO but not with PNO.

Conclusion-Patients with severe stable COPD have reduced levels of eNO compared with normal subjects. eNO levels are slightly related to the severity of airflow obstruction.

(Thorax 1998;53:881-883)
\end{abstract}

Keywords: exhaled nitric oxide; chronic obstructive pulmonary disease

Increased levels of exhaled nitric oxide (eNO), an index of $\mathrm{NO}$ synthesis in the respiratory system, ${ }^{1}$ have been detected in patients with asthma whereas smokers exhibit reduced levels of eNO. ${ }^{2}{ }^{3}$ Similar levels of eNO were found in patients with chronic obstructive pulmonary disease (COPD) and in healthy subjects. ${ }^{4}$ More recently Maziak et $a \bar{l}$ have shown a negative correlation between forced expiratory volume in one second $\left(\mathrm{FEV}_{1}\right)$ and eNO in patients with stable and exacerbated COPD. We wondered whether the levels of eNO might be influenced by the degree of severity of COPD as assessed by airway obstruction and by the presence or absence of cor pulmonale (CP). The aim of this study was therefore to measure the concentration of eNO in patients with stable COPD with different levels of airway obstruction, with and without CP.

\section{Methods}

SUBJECTS

Fifty three patients with COPD diagnosed according to the American Thoracic Society (ATS) criteria $^{6}$ were enrolled, with a mean increase in $\mathrm{FEV}_{1}$ following inhaled bronchodilator (200 mg salbutamol) of 6 (2)\% of the baseline. All patients were ex-smokers (mean pack years 24 (8)) without a history of atopy. At the start of the study they were all in a stable condition and had been free from exacerbations in the preceding four weeks. Patients with other organ failure, cancer, and inability to cooperate 
Table 1 Peak and plateau levels of expired nitric oxide (PNO and PLNO) in the study population and controls

\begin{tabular}{|c|c|c|c|c|}
\hline & \multirow[b]{2}{*}{ Mean (SD) } & \multirow{2}{*}{$\begin{array}{l}\text { Mean differences } \\
\text { vs controls }\end{array}$} & \multicolumn{2}{|c|}{ 95\% Confidence intervals } \\
\hline & & & + & - \\
\hline \multicolumn{5}{|l|}{ PNO (ppb) } \\
\hline Group 1 & $22.33(12.62)$ & -1.91 & 9.12 & -12.95 \\
\hline Group 2 & $19.97(14.81)$ & -4.27 & 8.02 & -16.56 \\
\hline Group 3 & $27.56(13.95)$ & 3.32 & 13.96 & -7.33 \\
\hline Controls & $24.24(9.09)$ & & & \\
\hline \multicolumn{5}{|l|}{ PLNO (ppb) } \\
\hline Group 1 & $5.53(2.93)^{\star}$ & -3.92 & -0.73 & -6.40 \\
\hline Group 2 & $5.75(3.52)^{\star}$ & -3.71 & -0.20 & -6.49 \\
\hline Group 3 & $7.07(2.75)$ & -2.39 & 0.44 & -4.50 \\
\hline Controls & $9.46(2.79)$ & & & \\
\hline
\end{tabular}

PLNO: general effect of one way ANOVA, F $(3.66)=4.9(\mathrm{p}<0.01)$.

*Significant post hoc difference at $\mathrm{p}<0.05$ levels (groups 1 and 2 versus group 3 and control).
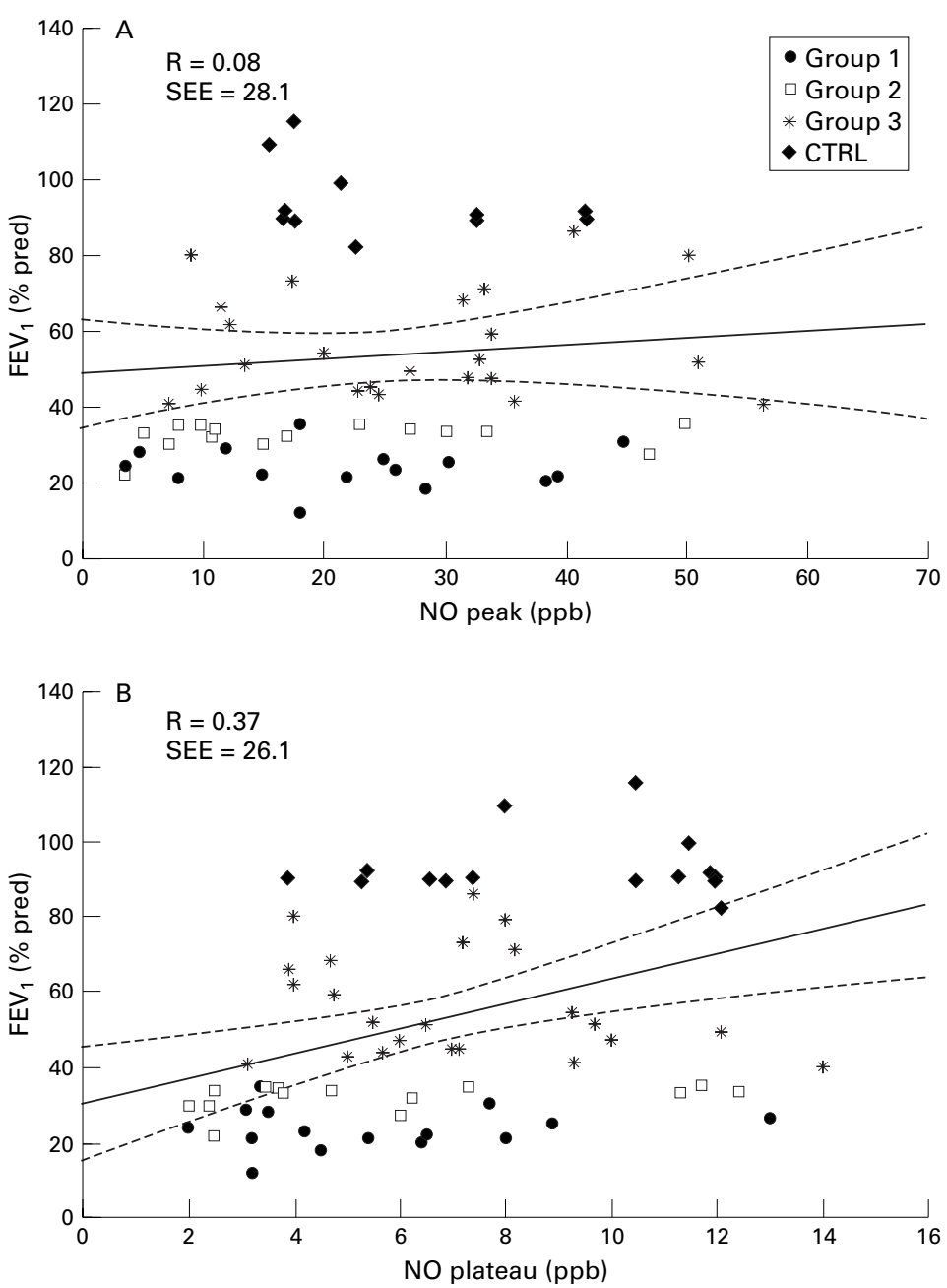

Figure 1 Scatterplot of linear regression by group between $F E V_{1} \%$ predicted and $(A)$ peak and (B) plateau levels of exhaled nitric oxide (eNO). The continuous line on each graph fit all data when the study subjects were considered as a single group. For details of groups, see text. residual volume (RV) $174(62) \%$ predicted, total lung volume (TLC) 105 (29)\% predicted); group $2, \mathrm{FEV}_{1}<35 \%$ predicted without $\mathrm{CP}(\mathrm{n}=$ 15, age 66 (9) years, $13 \mathrm{M}, \mathrm{FEV}_{1} 32$ (3)\% predicted, FVC 48 (8)\% predicted, RV 154 (36) $\%$ predicted, TLC 103 (22)\% predicted); group $3, \mathrm{FEV}_{1}>35 \%$ predicted $(\mathrm{n}=23$, age 67 (7) years, $21 \mathrm{M}, \mathrm{FEV}_{1} 56$ (10)\% predicted, FVC 69 (10)\% predicted, RV 130 (24)\% predicted, TLC 100 (12)\% predicted). Seventeen healthy non-smoking, non-atopic subjects (age 58 (11) years, $11 \mathrm{M}$ ) served as controls.

The study protocol was approved by the ethics committee of the Salvatore Maugeri Foundation, Gussago and the study was conducted according to the Declaration of Helsinki. Informed consent was obtained from the patients before enrolment into the study.

MEASUREMENTS

Static and dynamic lung volumes were measured with a volume constant body plethysmograph (CAD-NET System 1085, Medical Graphic Corp, St Pauls, Minnesota, USA). The predicted values were those of Quanjer.

The presence of cor pulmonale was assessed by echo-colour Doppler evaluation (Sonotron, VingMed 750, Milan, Italy) using a mean pulmonary artery pressure of $>35 \mathrm{~mm} \mathrm{Hg}$.

Exhaled nitric oxide was assessed with a high resolution $(0.3 \mathrm{ppb})$ chemoluminescence analyser (LR 2000 Series, Logan Research, Kent, UK) adapted for on-line recording of NO concentration and equipped with a Teflon mouthpiece tubing. This feature obviates the need for collection into a reservoir with its variable loss of reactive $\mathrm{NO}$; the sampling rate was $250 \mathrm{ml} / \mathrm{min}$. The analyser also measured $\mathrm{CO}_{2}$ (resolution $0.1 \%$, response time $0.2 \mathrm{~s}$ ) by single beam infrared absorption as well as mouth pressure, exhaled flow, and volume. Mouth pressure and flow rate were calibrated using a water manometer and calibration analyser (Timeter RT-200, SLE Ltd, UK). An internal restrictor in the breathing circuit allowed expiration against a resistance in order to keep the soft palate closed and to prevent contamination of exhaled air with nasal NO; a single breath manoeuvre was performed according to the previously described methodology. ${ }^{58}$ Peak and plateau values of NO (PNO and PLNO, respectively, in $\mathrm{ppb}$ ) were obtained from the eNO curve. The mean value of five reproducible measurements was used for analysis.

\section{STUDY DESIGN}

On the morning of the study day subjects free from medications for at least 12 hours performed spirometric tests according to the standard procedure. After a 30 minute rest in the sitting position they were asked to perform five consecutive manoeuvres to measure eNO according to the published recommendations. ${ }^{9}$

DATA ANALYSIS

All data are expressed as mean (SD). The PNO and PLNO values were transformed by square root to improve characteristics of data distribution. Intrapatient eNO data were analysed by
(SD) age 66 (7) years, FEV 23 (5)\% predict forced vital capacity (FVC) 39 (7)\% predicted, 
ANOVA for repeated measures with HuynhFeldt correction. As no significant difference within subjects was found, the mean of five consecutive measurements was used. The between group differences were evaluated by ANOVA and the post hoc test with Bonferroni correction was then used when requested. Linear regression by group was conducted to investigate the relationship between lung volumes and eNO variables in the study groups and to evaluate differences in slopes and intercepts. A p value of $<0.05$ was considered significant.

\section{Results}

Exhaled NO was detectable in all subjects. The mean (SD) coefficients of variation of intrapatient measurements were 5 (3)\% and 6 (4)\% for PNO and PLNO, respectively. The mean values of PLNO in patients with COPD were lower than in controls (table 1) but mean levels of PNO were not significantly different between the groups. All the patients with COPD had lower levels of PLNO than controls (6.3 (3.0) ppb and 9.4 (2.8) ppb, respectively). In groups 1 and 2 PLNO levels were significantly lower than in group 3 (5.5 (2.9), 5.7 (3.5), and 7.1 (2.7) ppb, p<0.01, ANOVA). The PLNO levels in patients in group 3 were not significantly lower than in controls but were significantly higher than in patients with more severe COPD, independent of the presence of CP.

The linear regression analysis by group on all data for $\mathrm{FEV}_{1} \%$ predicted versus PNO and PLNO (fig 1A and B) resulted in different slopes. A slight but significant correlation was found between $\mathrm{FEV}_{1}$ and PLNO $(r=0.37$, $\mathrm{p}<0.01)$ and a less significant $(\mathrm{p}<0.05)$ relationship was found between FVC \% predicted and PLNO. However, no significant correlations were found when only COPD data were analysed. No significant relationship was found between eNO (either assessed as PNO or PLNO) and RV and TLC, nor with the demographic data or previous smoking behaviour.

\section{Discussion}

The results of this study show that, in patients with COPD, eNO levels are lower than in normal non-smoker subjects and are reduced in patients with more severe airway obstruction independent of the presence of cor pulmonale.

Robbins $e t a l^{4}$ found that peak oral NO levels in COPD patients with a mean $\mathrm{FEV}_{1}$ of 46 (5) $\%$ predicted were not significantly different from normal controls without any correlation between $\mathrm{FEV}_{1}$ or FVC and eNO. However, we found that patients in group 3, who were suffering from similar levels of airflow obstruction, had lower PLNO levels than controls. In addition, we extended the study to more severe COPD patients, both with and without CP.

The single breath technique used in our study is strongly recommended. ${ }^{9}$ We are confident that a constant flow exhalation was performed even in the most compromised sub- jects, as verified by the back-up visual control on-line system (flow and pressure) and by the reproducibility of the obtained values (mean variation coefficient less than $10 \%$ for both PNO and PLNO).

PNO is considered to be the result of the addition of eNO from previous exhalation and the unavoidable nasal contribution. ${ }^{10}$ PLNO better represents the production from the distal airways. ${ }^{10}$ Indeed, the different results in PLNO and PNO confirm the different sources of the two components.

Decreased levels of eNO have been associated with cigarette smoking and were found to be inversely related to cigarette consumption. ${ }^{3}$ In our sample of ex-smoker subjects with COPD we failed to find any relationship between eNO and previous smoking habit (pack years). In a recent paper by Maziak et $a \bar{P}$ eight ex-smokers with COPD (mean $\mathrm{FEV}_{1} 48$ (5)\% predicted) had an eNO plateau level similar to that observed in our patients in group 3 .

Giaid and Saleh ${ }^{11}$ have recently shown a reduced expression of endothelial NO synthase in pulmonary arteries of patients with pulmonary hypertension. In our study the presence of $\mathrm{CP}$ was not associated with different levels of eNO, at least not in our most severe patients $\left(\mathrm{FEV}_{1}<35 \%\right.$ predicted).

The great scatter of individual values and the relatively small number of subjects could have limited the significance of the direct relationship between $\mathrm{FEV}_{1}$ or FVC and PLNO in our study group. In contrast to our results, Maziak et $a \bar{l}$ found an inverse relationship between $\mathrm{FEV}_{1}$ and eNO values in subjects with COPD and normal smoker controls. This is probably influenced by the fact that different groups involving smokers and ex-smokers were compared and by the presence of unstable COPD resulting in the development of acute infection and inflammation.

1 Leone AM, Gustafsson LE, Francis PL, et al. Nitric oxide is present in exhaled breath in humans: direct GC-MS confirmation. Biochem Biophys Res Commun 1994;201:883-7.

2 Barnes PJ, Kharitonov SA. Exhaled nitric oxide: a new lung function test. Thorax 1996;51:233-7.

3 Kharitonov SA, Robbins RA, Yates D, et al. Acute and chronic effects of cigarette smoking on exhaled nitric oxide. Am $\mathcal{F}$ Respir Crit Care Med 1995;152:609-12.

4 Robbins RA, Floreani AA, Von Essen SG, et al. Measurement of exhaled nitric oxide by three different techniques. Am 7 Respir Crit Care Med 1996;153:1631-5.

5 Maziak W, Loukides S, Culpitt S, et al. Exhaled nitric oxyde Maziak W, Loukides S, Culpitt S, et al. Exhaled nitric oxyde
in chronic obstructive pulmonary disease. Am $\mathcal{F}$ Respir Crit Care Med 1998;157:998-1002.

6 ATS statement. Standards for the diagnosis and care of patients with chronic obstructive pulmonary disease. $A m \mathcal{F}$ Respir Crit Care Med 1995;152:S77-120.

7 Quanjer PH. Working Party on Standardization of Lung Function Tests. Bull Eur Physiopathol Respir 1983;19(Suppl 5):7-10.

8 Kharitonov SA, Wells AU, O'Connor BJ, et al. Elevated levels of exhaled nitric oxide in bronchiectasis. Am $\mathcal{F}$ Respir Crit Care Med 1995;151:1889-93.

9 Kharitonov SA, Alving K, Barnes PJ. Exhaled and nasal nitric oxide measurements: recommendations. Eur Respir $\mathcal{F}$ 1997;10:1683-93.

10 Dillon WC, Hampl V, Shultz PJ, et al. Origins of breath nitric oxide in humans. Chest 1996;110:930-8.

11 Giaid A, Saleh D. Reduced expression of endothelial nitric oxide synthase in the lungs of patients with pulmonary hypertension. N Engl f Med 1995;333:214-21. 